\title{
Erratum to: Temperature, precipitation and biotic interactions as determinants of tree seedling recruitment across the tree line ecotone
}

\author{
Lise Tingstad $^{1,2} \cdot$ Siri Lie Olsen $^{3,4} \cdot$ Kari Klanderud $^{4} \cdot$ Vigdis Vandvik $^{1} \cdot$ \\ Mikael Ohlson ${ }^{4}$
}

Published online: 30 January 2016

(C) Springer-Verlag Berlin Heidelberg 2016

\section{Erratum to: Oecologia (2015) 179:599-608 \\ DOI 10.1007/s00442-015-3360-0}

During the review process of Tingstad et al. 2015 (Oecologia 179:599-608) data in Figs. 1 and 2, panels $b$ and d, for gap and intact vegetation were reversed and this error was not caught until after the paper was published. The correct figures, showing that spruce seedling emergence, establishment (Fig. 1b) and biomass (Fig. 2d) were higher in gaps but that seedlings in intact vegetation were taller (Fig. 2b) are published in this erratum.

The online version of the original article can be found under doi:10.1007/s00442-015-3360-0.

Lise Tingstad

lise.tingstad@bio.uib.no

Siri Lie Olsen

siri.lie.olsen@nina.no

Kari Klanderud

kari.klanderud@nmbu.no

Vigdis Vandvik

vigdis.vandvik@bio.uib.no

Mikael Ohlson

mikael.ohlson@nmbu.no

1 Department of Biology, University of Bergen, Bergen, Norway

2 Norwegian Forest and Landscape Institute, Bergen, Norway

3 Norwegian Institute for Nature Research, Oslo, Norway

4 Department of Ecology and Natural Resource Management, Norwegian University of Life Sciences, Ås, Norway 
Fig. 1 Observed patterns of tree seedling emergence and establishment in the 12 study sites in response to presence (intact vegetation) or absence (gap) of vegetation: a pine seedling emergence, $\mathbf{b}$ spruce seedling emergence, $\mathbf{c}$ pine seedling establishment and $\mathbf{d}$ spruce seedling establishment. Habitat types correspond to the temperature gradient: Alp alpine, Sub sub-alpine, Bor boreal. The cated with numbers $1-4$ from dry to wet (see Table 1). Bars show mean $\pm \mathrm{SE}, N=5$ precipitation gradient is indi-
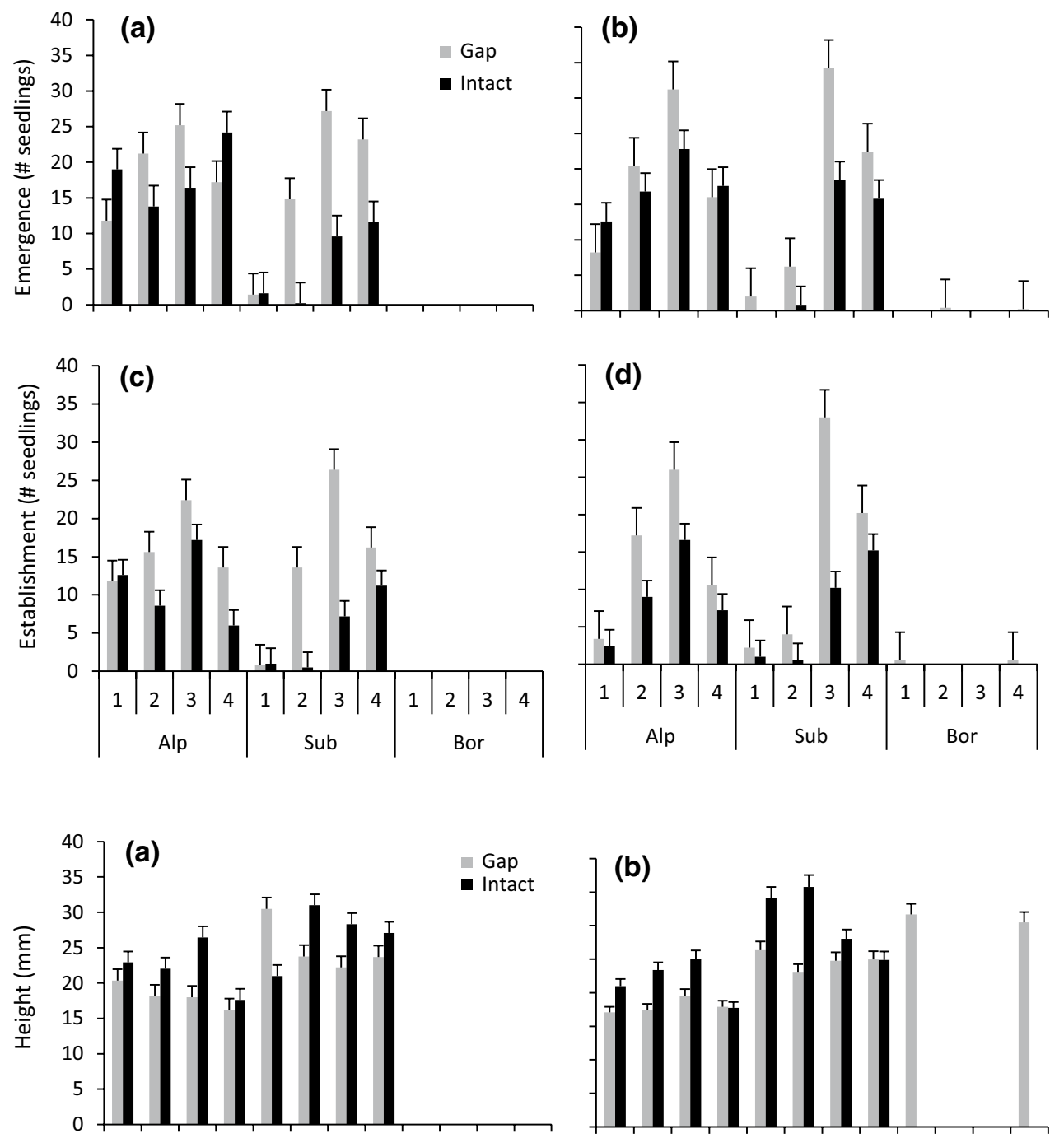

Fig. 2 Observed patterns of tree seedling height and aboveground biomass in the 12 study sites in response to presence (intact vegetation) or absence (gap) of vegetation: a pine seedling height, $\mathbf{b}$ spruce seedling height, c pine seedling biomass, $\mathbf{d}$ spruce seedling biomass. Habitat types correspond to the temperature gradient: Alp alpine, Sub sub-alpine, Bor boreal. The precipitation gradient is indicated with numbers 1-4 from dry to wet (see Table 1). Bars show mean \pm SE. $N=5$
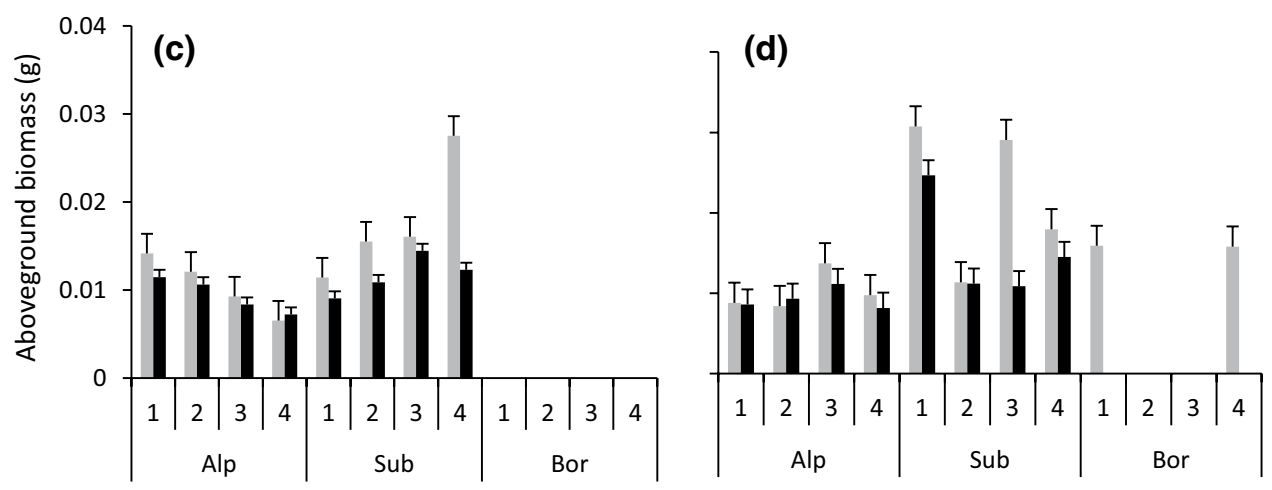